\title{
The effect of low dose ketamine and priming of cisatracurium on the intubating condition and onset time of cisatracurium
}

\author{
Byung-Ryang Ahn' ${ }^{2}$, Sang-Hun Kim ${ }^{1,2}$, Byung-Sik Yu ${ }^{1,2}$, Kyung-Joon Lim ${ }^{1,2}$, and Jong-June Sun ${ }^{2}$ \\ Department of Anesthesiology and Pain Medicine, ${ }^{1}$ Chosun University School of Medicine, ${ }^{2}$ Chosun University Hospital, Gwangju, Korea
}

Background: Both ketamine and priming may accelerate the onset time of neuromuscular blocking agents. We investigate the effect of low dose ketamine and cisatracurium priming on the intubating condition and onset time of cisatracurium.

Methods: After Institutional Review Board approval, 120 consecutive patients undergoing general anesthesia were randomly assigned to one of 4 groups. All patients were injected one of normal saline (group C), cisatracurium 0.01 $\mathrm{mg} / \mathrm{kg}$ (group P), ketamine $0.5 \mathrm{mg} / \mathrm{kg}$ (group K) and combination of cisatracurium $0.01 \mathrm{mg} / \mathrm{kg}$, and ketamine $0.5 \mathrm{mg} /$ $\mathrm{kg}$ (group PK) diluted into a $5 \mathrm{ml}$ solution, followed 3 minutes later by cisatracurium $0.15 \mathrm{mg} / \mathrm{kg}$ in group C and $\mathrm{K}$, and $0.14 \mathrm{mg} / \mathrm{kg}$ cisatracurium in priming group. Onset time was recorded the electromyographical responses using single twitch and intubating conditions were evaluated at 60 seconds after cisatracurium administration.

Results: The mean onset time was most significantly accelerated in Group PK and was also significantly more accelerated in Group P and K compared with Group C (P < 0.008). It was $112.7 \pm 13.2,91.4 \pm 17.9,84.9 \pm 12.7$ and $76.4 \pm 8.3$ seconds in Group C, P, K, and PK, respectively. Intubating conditions were significantly improved in Group P, K and PK than Group C (P < 0.008). Especially, Group PK showed most significant improvement of intubating conditions.

Conclusions: The combination of the low dose ketamine and cisatracurium priming accelerated the onset time and was improved the intubating conditions. (Korean J Anesthesiol 2012; 63: 308-313)

Key Words: Cisatracurium, Intubation, Ketamine, Onset, Priming.

Received: March 8, 2012. Revised: April 2, 2012. Accepted: April 25, 2012.

Corresponding author: Sang-Hun Kim, M.D., Ph.D., Department of Anesthesiology and Pain Medicine, Chosun University School of Medicine, 588, Seasuk-dong, Dong-gu, Gwangju 501-717, Korea. Tel: 82-62-220-3223, Fax: 82-62-223-2333, E-mail: ksh3223@chosun.ac.kr This is a thesis for a master's degree.

(c) This is an open-access article distributed under the terms of the Creative Commons Attribution Non-Commercial License (http:// creativecommons.org/licenses/by-nc/3.0/), which permits unrestricted non-commercial use, distribution, and reproduction in any medium, provided the original work is properly cited. 


\section{Introduction}

In the past, succinylcholine was usually used for rapid sequence intubation. Although it is suitable for this purpose, its many potential complications have led to searching for an alternatives and developing of new neuromuscular blocking agents (NMBAs) for rapid intubation. However, these NMBAs do not provide the satisfactory rapid tracheal intubating conditions in every situation because of their different pharmacologic properties. One of pharmacologic properties, the onset time of NMBAs is an important factor during a rapid sequence induction. Therefore, many efforts have been made to use the existing MNBAs by reducing onset time. In these efforts, priming of NMBAs, administration of a small dose of the drug before the larger intubating dose, was commonly used to accelerate the onset time [1-4]. Other focus to reduce the onset time was on modifying hemodynamic factors such as cardiac output, circulation time and perfusion of muscles [2]. Its supporting hypothesis was that induction agents that increased cardiac output and perfusion of muscles can reach the NMBAs to the neuromuscular junction more rapidly, and it result in accelerating of the onset time $[5,6]$.

Recent reports have been reported that ketamine was associated with better intubating conditions, resulting from increase the cardiac output. However, there was controversy in the effect of ketamine on the onset time of rocuronium $[5,7,8]$. Cisatracurium and rocuronium are relatively recently introduced non-depolarizing muscle relaxants. Although they have similar hemodynamic effects, cisatracurium has a relatively long onset time that discourages rapid-sequence induction [9-12].

We hypothesized that low dose ketamine would improve intubating conditions after cisatracurium while accelerating the onset time, and priming of cisatracurium also improve them further more. The purpose of this study was to investigate the effects of both low dose ketamine and priming, given before the induction of anesthesia, on the onset time of cisatracurium and the intubating conditions.

\section{Materials and Methods}

The Institutional Review Board approved this prospective randomized placebo-controlled trial. Written informed consent was obtained from all patients. We recruited the American Society of Anesthesiologists (ASA) physical status I or II patients, aged 18-65 years, scheduled for elective surgery. The study protocol adhered to the published guidelines on pharmacodynamic studies of NMBA. Patients with an allergy to cisatracurium, neuromuscular disease, expected difficult mask ventilation or intubation, receiving medications known to influence neuromuscular function (for instance, calcium channel blocker, aminoglycosides or phenytoine), electrolyte abnormalities, hepatic or renal insufficiency, a body mass index $<19$ or $>28$, and pregnant or breastfeeding women were excluded from the study subjects. No significant differences in age, gender, height, and weight were found among all the groups.

All patients were pre-medicated with midazolam $0.05 \mathrm{mg} /$ $\mathrm{kg}$, intramuscularly, 30 minute before anesthesia. Standard monitoring included an ECG, non-invasive blood pressure, endtidal partial pressure of carbon dioxide, and peripheral pulse oximetry. Study medications were produced and randomized (using a random number table) by the non-investigable nurse as indistinguishable, numbered syringes.

All patients were allocated to one of four groups of 30 patients each. They were injected one of normal saline (group C), cisatracurium $0.01 \mathrm{mg} / \mathrm{kg}$ (group P), ketamine $0.5 \mathrm{mg} /$ $\mathrm{kg}$ (group $\mathrm{K}$ ) and combination of cisatracurium $0.01 \mathrm{mg} /$ $\mathrm{kg}$ and ketamine $0.5 \mathrm{mg} / \mathrm{kg}$ (group PK) diluted into a $5 \mathrm{ml}$ solution before induction. Anesthesia was induced with the targeted effect-site concentration of propofol $4 \mu \mathrm{g} / \mathrm{ml}$ and remifentanil $3 \mathrm{ng} / \mathrm{ml}$ based on a Minto pharmacokinetic model using a TCI device (Orchestra ${ }^{\circledR}$ Base Primea, Fresenius-Vial, France), followed 3 minute later by cisatracurium $0.15 \mathrm{mg} / \mathrm{kg}$ in group $\mathrm{C}$ and $\mathrm{K}$, and $0.14 \mathrm{mg} / \mathrm{kg}$ cisatracurium, in priming groups, diluted into a $10 \mathrm{ml}$ solution. For the maintenance of anesthesia, a propofol effect-site concentration of $3 \pm 2 \mu \mathrm{g} /$ $\mathrm{mL}$ and a remifentanil effect-site concentration of $3 \pm 0.5 \mathrm{ng} /$ $\mathrm{ml}$ with $50 \%$ oxygen-air mixture were used. Time sequence of laryngoscopy and intubation should be clearly recorded. For example, when intubation is planned to be carried out at $1 \mathrm{~min}$, laryngoscopy should be started at $50 \mathrm{~s}$ and intubation carried out at $60 \mathrm{~s}$, being completed within $20 \mathrm{~s}$. To avoid vocal cord injury, tracheal intubation was not attempted if the vocal cords were fully closed, in which case, intubation was reattempted 30 $s$ later. The intubating conditions were evaluated by the criteria established by Fuchs-Buder et al. (Table 1) [13]. Mean blood pressure (MBP) and heart rate (HR) were measured before the injection of study drugs and after the first trial of tracheal intubation. In addition, muscle weakness, dysphasia, and respiratory failure were also monitored.

Neuromuscular function was assessed by electromyography of the adductor pollicis on the opposite side to blood pressure cuff and intravenous line with a single twitch using the neuromuscular transmission module and was displayed on an anesthetic monitoring system (Anesthetic Monitoring System $\mathrm{S} / 5^{\mathrm{TM}}$, Datex-Ohmeda Inc., Helsinki, Finland). The stimulus current needed to achieve the maximal response of the adductor pollicis muscle was automatically searched in each patient. It began with $10 \mathrm{~mA}$ single twitch stimuli of $0.2 \mathrm{~ms}$ duration applied every $1 \mathrm{~s}$ in steps of $5 \mathrm{~mA}$. And then, the stimulating 
Table 1. Assessment of Intubating Conditions (According to Fuchs-Buder et al. [13])

Evaluation of intubating conditions*

\begin{tabular}{|c|c|c|c|}
\hline \multirow{2}{*}{ Variable assessed } & \multicolumn{2}{|c|}{ Clinically acceptable } & \multirow{2}{*}{$\frac{\text { Not clinically acceptable }}{\text { Poor }}$} \\
\hline & Excellent & Good & \\
\hline 1. Laryngoscopy ${ }^{\dagger}$ & Easy & Fair & Difficult \\
\hline 2. Vocal cord position & Abducted & Intermediate/moving & Closed \\
\hline $\begin{array}{l}\text { 3. Reaction to insertion of the tracheal tube and cuff } \\
\text { inflation (Diaphragmatic movement/coughing) }\end{array}$ & None & Slight $^{\dagger}$ & Vigorous/sustained $^{\S}$ \\
\hline
\end{tabular}

*Intubating conditions. Excellent: all qualities are excellent, Good: all qualities are either excellent or good, Poor: the presence of a single quality listed under 'poor'. ' Laryngoscopy. Easy: jaw relaxed, no resistance to blade insertion, Fair: jaw not fully relaxed slight resistance to blade insertion, Difficult: poor jaw relaxation, active resistance of the patient to laryngoscopy. ${ }^{\dagger}$ One to two weak contractions or movement for less than $5 \mathrm{~s}$.

${ }^{\S}$ More than two contractions and/or movement for longer than $5 \mathrm{~s}$.

Table 2. Demographic Data and Supramaximal Current

\begin{tabular}{lcccc}
\hline & $\begin{array}{c}\text { Group C } \\
(\mathrm{n}=30)\end{array}$ & $\begin{array}{c}\text { Group P } \\
(\mathrm{n}=30)\end{array}$ & $\begin{array}{c}\text { Group K } \\
(\mathrm{n}=30)\end{array}$ & $\begin{array}{c}\text { Group PK } \\
(\mathrm{n}=30)\end{array}$ \\
\hline Sex (M/F) & $20 / 10$ & $15 / 15$ & $17 / 13$ & $13 / 17$ \\
Age (yr) & $44.9 \pm 12.5$ & $41.3 \pm 13.5$ & $42.6 \pm 14.6$ & $45.9 \pm 8.3$ \\
Height (cm) & $165.9 \pm 10.0$ & $165.0 \pm 10.1$ & $167.6 \pm 8.2$ & $161.5 \pm 9.2$ \\
Weight (kg) & $66.7 \pm 10.4$ & $63.9 \pm 13.9$ & $65.7 \pm 11.1$ & $63.4 \pm 13.4$ \\
Supramaximal current (mA) & $35.8 \pm 8.1$ & $36.3 \pm 11.2$ & $35.0 \pm 9.4$ & $30.9 \pm 7.6$ \\
\hline
\end{tabular}

Values are expressed as mean \pm SD, numbers of patient. There are no significant differences between groups. Groups divided according to injection of normal saline (group C), cisatracurium $0.01 \mathrm{mg} / \mathrm{kg}$ (group P), ketamine $0.5 \mathrm{mg} / \mathrm{kg}$ (group K) and combination of cisatracurium 0.01 $\mathrm{mg} / \mathrm{kg}$ and ketamine $0.5 \mathrm{mg} / \mathrm{kg}$ (group PK) diluted into a $5 \mathrm{ml}$ solution before induction.

current was automatically increased by $15 \%$ to produce a supramaximal current. If the supramaximal current was not found or the response was too weak, the current was set at 70 mA. Each patient's supramaximal stimulation was applied with $0.2 \mathrm{~ms}$ duration square waves and 1 second interval, at $1 \mathrm{~Hz}$. After having obtained stable baseline measurements and induction of anesthesia, a bolus dose of cisatracurium $0.15 \mathrm{mg} / \mathrm{kg}$ was administered intravenously. Simultaneously, measurements were measured by single twitch method or computed as follows: (1) the time in seconds from the start of injection of cisatracurium until the first change of single twitch response (lag time; LT); (2) the time in seconds from the start of injection of cisatracurium until 95\% depression of the single twitch (Onset time, OT).

Sample size was calculated that 30 patients per group were required with a 0.05 level of significance and $80 \%$ power to detect the improvement at least with a $50 \%$ difference between the control group and any of the other three groups with respect to intubating conditions.

SPSS (Windows ver. 19.0, SPSS Inc., Chicago, IL) was used for statistical analysis. All the values that were measured were summarized by descriptive statistics (number of patients, mean \pm standard deviation or medians and ranges) or frequency distributions (number of patients and percentages), as appropriate. For height, weight, and supramaximal current, one-way
ANOVA test was used and if a significant difference was found, a Bonferroni Post-Hoc test was used. For gender, $\mathrm{x}^{2}$ tests were used for analysis. For all data except of sex, height, weight and supramaximal current, Kruskal-Wallis test was used and if a significant difference was found, Mann-Whitney test for PostHoc test was used. $\mathrm{P}$ values $<0.05$ for sex, height, weight and supramaximal current, and $\mathrm{P}$ values $<0.008$ for others using a non-parametric test were considered statistically significant.

\section{Results}

A total of 120 patients received the assigned study treatment and no patients were withdrawn due to refusal, missed data and adverse effects during the study. No significant differences in age, gender, height, weight and supramaximal current were found among all the groups (Table 2). MAP and HR before induction of anesthesia did not differ significantly between groups.

There was most significant accelerate in Group PK than others on the lag time and onset time $(\mathrm{P}<0.008)$. There was also significantly more accelerated in Group $\mathrm{P}$ and K compared with Group C $(\mathrm{P}<0.008)$, but there was no differences between group $\mathrm{P}$ and $\mathrm{K}$ (Fig. 1). The onset time was on average $112.7 \pm$ $13.2,91.4 \pm 17.9,84.9 \pm 12.7,76.4 \pm 8.3$ seconds in Group C, P, K and PK, respectively (Fig. 1). The lag time was on average 50.4 


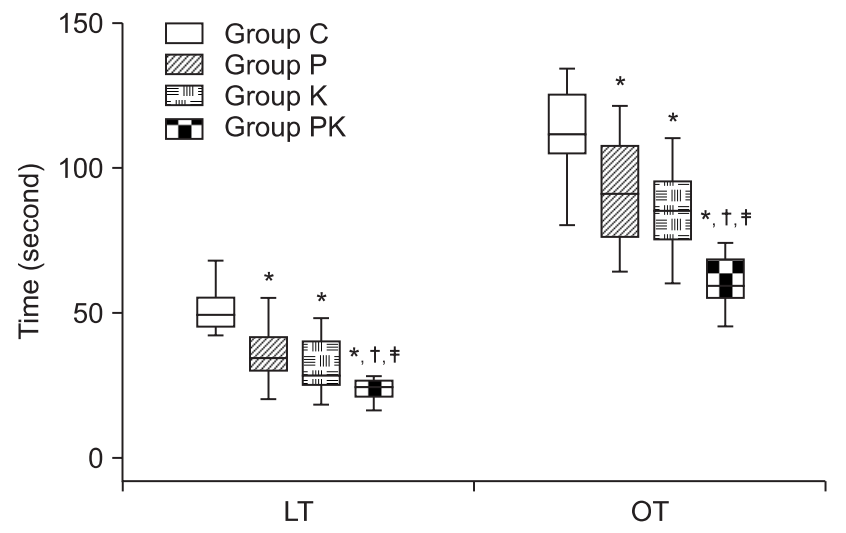

Fig. 1. Lag time (LT), onset time (OT). There is most significant accelerate in Group PK than others on the lag time, onset time and supramaximal suppression of single twitch. There are also significantly more accelerated in Group $\mathrm{P}$ and $\mathrm{K}$ compared with Group C, but there are no differences between group P and K. LT is the time in seconds from the start of injection of cisatracurium until the first change of single twitch response. OT is the time until 95\% depression of the single twitch. Groups divided according to injection of normal saline (group C), cisatracurium $0.01 \mathrm{mg} /$ $\mathrm{kg}$ (group P), ketamine $0.5 \mathrm{mg} / \mathrm{kg}$ (group $\mathrm{K}$ ) and combination of cisatracurium $0.01 \mathrm{mg} / \mathrm{kg}$ and ketamine $0.5 \mathrm{mg} / \mathrm{kg}$ (group PK) diluted into a $5 \mathrm{ml}$ solution before induction. $* \mathrm{P}<0.008$ vs. Group $\mathrm{C}$, ${ }^{\dagger} \mathrm{P}<0.008$ vs. Group $\mathrm{P},{ }^{\ddagger} \mathrm{P}<0.008$ vs. Group K (Mann-Whitney test).

\pm 6.5, $37.4 \pm 12.1,30.5 \pm 9.3,23.4 \pm 3.2$ seconds in Group C, P, K and PK, respectively (Fig. 1).

In intubating conditions, 'excellent' was most significantly higher in Group PK than others $(\mathrm{P}<0.008)$ and significantly higher in Group P and K compared with Group C ( $<<0.008)$. However, there were no differences between group $\mathrm{P}$ and $\mathrm{K}$ $(3.3 \%, 36.7 \%, 26.7 \%$ and $70 \%$ in Group C, P, K and PK, respectively) (Fig. 2).

Finally, even if we did not described in tables, the MBP and HR just after the first trial of tracheal intubation were higher in group $\mathrm{K}$ and $\mathrm{PK}$ than in group $\mathrm{C}$ and $\mathrm{P}$. MBP was $84.9 \pm 6.0$, 85.43 $\pm 7.0,87.6 \pm 4.2$, and 87.6 $\pm 8.9 \mathrm{mmHg}$ in Group C, P, K and $\mathrm{PK}$, respectively. $\mathrm{HR}$ was $73.2 \pm 5.9,73.1 \pm 5.9,76.2 \pm 4.2$, and $76.1 \pm 5.0$ beat $/ \mathrm{min}$ in Group C, P, K and PK, respectively. There were no significant differences changes between groups.

There were no signs of muscular weakness, evidences of respiratory difficulty and adverse effects related to ketamine administration.

\section{Discussion}

In this study, low dose ketamine, priming of cisatracurium or the combination of both agents was showed to improve the intubating conditions and accelerate the onset time of cisatracurium, especially the combination of low dose ketamine $(0.5 \mathrm{mg} / \mathrm{kg})$ and priming $(0.01 \mathrm{mg} / \mathrm{kg}$ cisatracurium $)$ provided

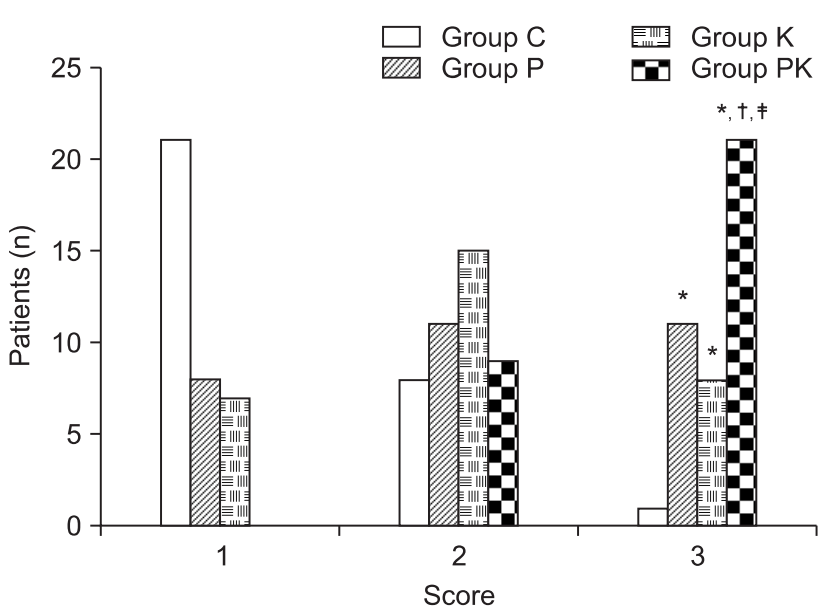

Fig. 2. Intubating conditions at 60 seconds after cisatracurium administration. 'Excellent' is most significantly higher in Group PK without poor intubating conditions than others, and also significantly higher in Group P and K compared with Group C. However, there are no differences between group P and K. $1=$ Poor, 2 = good, 3 = Excellent. Groups divide according to injection of normal saline (group C), cisatracurium $0.01 \mathrm{mg} / \mathrm{kg}$ (group P), ketamine 0.5 $\mathrm{mg} / \mathrm{kg}$ (group $\mathrm{K}$ ) and combination of cisatracurium $0.01 \mathrm{mg} / \mathrm{kg}$ and ketamine $0.5 \mathrm{mg} / \mathrm{kg}$ (group PK) diluted into a $5 \mathrm{ml}$ solution before induction. ${ }^{*} \mathrm{P}<0.008$ vs. Group $\mathrm{C},{ }^{\dagger} \mathrm{P}<0.008$ vs. Group $\mathrm{P},{ }^{\ddagger} \mathrm{P}<0.008$ vs. Group K (Mann-Whitney test).

the intubating conditions and the shorter onset time as enough as for rapid tracheal intubation.

Intubating condition can be influenced by physiologic factors, such as the onset time of NMBAs itself, cardiac output and perfusion of muscles. Cardiac output, one of these factors, can be maintained by administration of agents such as ephedrine, etomidate and ketamine. In ketamine study, there were the similar results on the intubating condition, but were debate Hans et al. [5] reported that high dose (2.5 $\mathrm{mg} / \mathrm{kg}$ ) of ketamine for induction of anesthesia provided the excellent and good intubating conditions in $100 \%$ of patients one minute after $0.6 \mathrm{mg} / \mathrm{kg}$ rocuronium injection. They suggested that the better condition in ketamine pretreatment resulted from either better laryngeal relaxation or a deeper level of anesthesia, and higher cardiac output could shorten the onset time of NMBAs despite there was not significant different. Baraka et al. [7] also demonstrated that $1.5 \mathrm{mg} /$ kg ketamine could provide the excellent or good intubating condition in all patients, but could not significantly shorten the onset time of NMBAs. Topcuoglu et al. [8] demonstrated that a low-dose $(0.5 \mathrm{mg} / \mathrm{kg})$ ketamine, the priming of rocuronium or combination of these improved intubating conditions and accelerated the onset time of rocuronium, but according to the result of stepwise regression test, the accelerated onset time and improved intubating condition were correlated with a low dose ketamine rather than priming of rocuronium. In a similar 
study, they demonstrated that the combination of the priming and low dose ephedrine provided better intubating conditions compared with the other groups at 60 seconds after $0.15 \mathrm{mg} / \mathrm{kg}$ cisatracurium [14]. In addition, many previous reports already revealed that the priming of cisatracurium shortened the onset time of cisatracurium $[15,16]$. Deepika et al. [16] showed that the priming with $0.01 \mathrm{mg} / \mathrm{kg}$, followed by the $0.14 \mathrm{mg} / \mathrm{kg}$ cisatracurium provided good to excellent intubating conditions in all patients and can offer an onset time comparable to or faster than the recommended dose of $0.2 \mathrm{mg} / \mathrm{kg}$. In our study, low dose ketamine was used along with cisatracurium priming during induction with propofol, and the results on the onset time were somewhat different to the mentioned previous study. Intubating conditions were better and the onset time was shorter in the low dose ketamine alone, the priming alone and the combination of these than control group. Especially, the combination of low dose ketamine and priming of cisatracurium provided the best intubating conditions and most significantly shortened onset time. We speculate that previous studies with the insignificant results about the effect of ketamine on the onset time enrolled too small sample size [5, 7]. Their results showed the propensity to accelerate the onset time but they did not reveal the significant differences. If they enrolled at least above 30 patients in each groups in their study, they might show the significant differences.

There are some possible explanations of good intubating condition and the different results on the onset time. First, ketamine can compensate the propofol's hemodynamic changes such as hypotension and bradycardia, result in maintaining blood pressures and heart rates. We detected that blood pressure and heart rate were slightly higher in ketamine groups than priming and control group even though it was not significant. Topcuoglu et al. [8] demonstrated the similar results and suggested that ketamine's effect on the blood pressure and heart rate causes rapid delivery of NMBAs to the synaptic cleft, consequently results in providing the good intubating conditions. Second, ketamine's analgesic and hypnotic effects can provide the deep anesthesia and obtund airway reflexes. We did not reduce the infusion dose of propofol in all groups, and a synergic effect between propofol and ketamine may cause the deep anesthesia favoring intubating conditions [17]. Third, we speculate that differences in the pharmacodynamic properties of NMBAs reflect differences in the effect of ketamine on the onset time. Most authors studied the effect of ketamine on the onset time of NMBAs that have faster onset time compared with cisatracurium, and reported that ketamine did not significantly effective in shortening the onset time $[5,7]$. Only one report demonstrated that the low dose ketamine is effective to reduce the onset time of rocuronium [8]. None of them explained the cause of these different results on the onset time. According to the previous reports, we suggest that the shorter the baseline onset time of the NMBA, such as rocuronium, the less effect of low dose ketamine would have on its reduction.

In the time of assessment of intubating conditions, most previous studies were performed at 60 to 90 seconds to compare with the onset time of succinylcholine $[5,6,8,14]$. In this study, we performed the tracheal intubation at 60 seconds because we want to see if study agents contributed to improve the intubating conditions and accelerate the onset time of cisatracurium as enough as a alternative of succinylcholine.

As an alternative to succinylcholine, high doses of NMBAs have been used for rapid sequence intubation. $0.15 \mathrm{mg} / \mathrm{kg}$ of cisatracurium $\left(3 \times \mathrm{ED}_{95}\right)$ provided intubating conditions within 90 seconds and its mean onset time was 3.4 minute, which was not sufficient as an alternative to succinylcholine [18]. In our combination of low dose ketamine and priming, the mean onset time was 76.4 seconds, which was significantly accelerated compared with $0.15 \mathrm{mg} / \mathrm{kg}$ of cisatracurium alone. However, priming may result in adverse effects such as muscle weakness, dysphasia, and respiratory failure. Thus, we have to pay attention to decide the priming dose. No adverse effects were reported in recent studies that used a priming dose of cisatracurium $0.01 \mathrm{mg} / \mathrm{kg}[9,16,19]$. Schmidt et al. [19] demonstrated that high dose of priming of cisatracurium was effective to shorten the onset time of cisatracurium, but did not not recommended clinical routine use due to possible side-effects. In our study, we used the same priming dose and priming interval as in Schmidt's study (cisatracurium $0.01 \mathrm{mg} / \mathrm{kg}$, 3 minutes) and our findings were similar from Schmidt et al. [19].

In conclusion, we demonstrate that the low dose $(0.5 \mathrm{mg} /$ $\mathrm{kg}$ ) ketamine alone as well as the priming cisatracurium $(0.01$ $\mathrm{mg} / \mathrm{kg}$ ) provide the satisfactory intubating conditions and accelerate the onset time of cisatracurium, furthermore the combination of them provide the most significantly improve intubating conditions and shorten the onset time.

\section{References}

1. Waud DR. The rate of action of competitive neuromuscular blocking agents. J Pharmacol Exp Ther 1967; 158: 99-114.

2. Donati F. Onset of action of relaxants. Can J Anaesth 1988; 35: S52-8.

3. Naguib M, Abdullatif M, Absood GH. The optimal priming dose for atracurium. Can Anaesth Soc J 1986; 33: 453-7.

4. Miller RD. The priming principle. Anesthesiology 1985; 62: 381-2.

5. Hans P, Brichant JF, Hubert B, Dewandre PY, Lamy M. Influence of induction of anaesthesia on intubating conditions one minute after rocuronium administration: comparison of ketamine and thiopentone. Anaesthesia 1999; 54: 276-9.

6. Ledowski T, Wulf $\mathrm{H}$. The influence of fentanyl vs. s-ketamine on intubating conditions during induction of anaesthesia with etomidate and rocuronium. Eur J Anaesthesiol 2001; 18: 519-23. 
7. Baraka AS, Sayyid SS, Assaf BA. Thiopental-rocuronium versus ketamine-rocuronium for rapid-sequence intubation in parturients undergoing cesarean section. Anesth Analg 1997; 84: 1104-7.

8. Topcuoglu PT, Uzun S, Canbay O, Pamuk G, Ozgen S. Ketamine, but not priming, improves intubating conditions during a propofolrocuronium induction. Can J Anaesth 2010; 57: 113-9.

9. Lin SP, Chang KY, Chen YJ, Lin SM, Chang WK, Chan KH, et al. Priming with rocuronium to accelerate the onset time of cisatracurium during intubation. J Chin Med Assoc 2009; 72: 15-9.

10. Amin AM, Mohammad MY, Ibrahim MF. Comparative study of neuromuscular blocking and hemodynamic effects of rocuronium and cisatracurium under sevoflurane or total intravenous anesthesia. Middle East J Anesthesiol 2009; 20: 39-51.

11. Kisor DF, Schmith VD. Clinical pharmacokinetics of cisatracurium besilate. Clin Pharmacokinet 1999; 36: 27-40.

12. Leykin Y, Pellis T, Vincenti E. Highlights in muscle relaxants. Expert Rev Neurother 2006; 6: 1833-43.

13. Fuchs-Buder T, Claudius C, Skovgaard LT, Eriksson LI, Mirakhur RK, Viby-Mogensen J. Good clinical research practice in pharmacodynamic studies of neuromuscular blocking agents II: the
Stockholm revision. Acta Anaesthesiol Scand 2007; 51: 789-808.

14. Leykin Y, Dalsasso M, Setti T, Pellis T. The effects of low-dose ephedrine on intubating conditions following low-dose priming with cisatracurium. J Clin Anesth 2010; 22: 425-31.

15. Mak PH, Irwin MG. The effect of cisatracurium and rocuronium on cisatracurium precurarization and the priming principle. J Clin Anesth 2004; 16: 83-7.

16. Deepika K, Kenaan CA, Bikhazi GB, Martineau DB. Influence of the priming technique on pharmacodynamics and intubating conditions of cisatracurium. J Clin Anesth 1999; 11: 572-5.

17. Hendrickx JF, Eger EI 2nd, Sonner JM, Shafer SL. Is synergy the rule? A review of anesthetic interactions producing hypnosis and immobility. Anesth Analg 2008; 107: 494-506.

18. Bluestein LS, Stinson LW Jr, Lennon RL, Quessy SN, Wilson RM. Evaluation of cisatracurium, a new neuromuscular blocking agent, for tracheal intubation. Can J Anaesth 1996; 43: 925-31.

19. Schmidt J, Albrecht S, Petterich N, Fechner J, Klein P, Irouschek A. Priming technique with cisatracurium Onset time at the laryngeal muscles. Anaesthesist 2007; 56: 992-1000. 